\title{
SUBSTANTIATION ON SHORT TERM EFFICACY AND SAFETY OF INSULIN ANALOGUES IN NORTH INDIAN SUPERSPECIALITY HOSPITAL
}

\author{
Mohammad Ali Koladi ${ }^{1}$, Chandar Batra ${ }^{2}$, Mohammad Akhtar ${ }^{3}$, Shoaib Ahmad ${ }^{4}$, Shibli \\ Jameel Ahmad ${ }^{3}$, and Shah Alam Khan ${ }^{5 *}$
}

\begin{abstract}
1.Al Khaleejy Polyclinics, Riyadh, Kingdom of Saudi Arabia,

2.Dept of Endocrinology, Indraprastha Apollo Hospitals, New Delhi, India

3.Dept of Pharma, Faculty of Pharmacy, Jamia Hamdard, New Delhi, India

4.Rayat \& Bahra Institute of Pharmacy, Sahauran, India

5.Dept. of Pharmacy, Oman Medical College, Muscat, Sultanate of Oman.
\end{abstract}

Submitted: $12-03-2014$

Revised: 04-05-2014

Accepted: 06-06-2014

*Corresponding author

Shah Alam Khan

Email :

shahalamkhan@yahoo.com

\section{ABSTRACT}

Diabetes mellitus is associated with high morbidity and mortality among patients and its prevalence is increasing at an alarming rate worldwide. Insulin analogues are reported to have better efficacy and safety as compared to conventional insulin therapy, however, substantiation of data in different geographical areas with genomic variation is yet to be established. The study was aimed to evaluate and compare the effectiveness and clinical safety profile of insulin analogues with regular insulin. In this prospective, randomized, observational study conducted at a Superspeciality hospital in India,78 diabetic patients on insulin therapy were recruited. The efficacy and safety markers of 24 patients on biphasic insulin analogue, 33 on recombinant insulin analogue and 21 on regular insulin were observed for 13 weeks. The collected data was statistically analyzed by using Instat software.The efficacy markers such as glycosylated hemoglobin, fasting and postprandial glucose values showed superior improvement with the insulin analogues at the end of 13 weeks study. Insulin analogues produced significantly fewer incidents of minor hypoglycemia without any significant alteration in BMI and weight gain. The results of our studies suggest that insulin analogues are safer and effective with regards to glycemic control and in the event of hypoglycemia over regular insulin.

Key words: Body mass index, Diabetes mellitus, Insulin analogue, Indian population, glycosylated hemoglobin

\section{INTRODUCTION}

Diabetes mellitus is a chronic metabolic disorder and its prevalence is increasing at an alarming rate especially in low and middle income nations. According to International Diabetes Federation, number of diabetic patients will rise from an estimated 285 million in 2010 to approximately 438 million in 2030 (International Diabetes Federation, 2009). India ranks first in prevalence of diabetes and as per the WHO estimate there will be around 87 million diabetics in India by the year 2030 (Bjork et al., 2003). Diabetes places a considerable burden on national economy and also if left uncontrolled, serious complications ensue that present larger morbid conditions which often result in mortality. Thus good glycemic control, to maintain glycosylated hemoglobin $\left(\mathrm{HbA}_{1 \mathrm{c}}\right)$ concentration of $7 \%$ or less, must be observed to reduce the risk of development of the severe complications (American Diabetes Association, 2014).

Current therapeutic approaches, pharmacological and life style modifications, merely control the condition and the therapy is needed lifelong (Dipiro et al., 2008). Insulin is the original and most effective treatment to manage type 1 and type 2 diabetes if exercise, diet or oral hypoglycemic agents failed to achieve the normal glycemia (Canadian Diabetes Association, 2003). The pharmacokinetics following subcutaneous injection of the currently available rapid, intermediate and long acting insulin preparations are unable to achieve normoglycemia because these agents do not replicate the pattern of basal and postprandial endogenous secretion of insulin in normal subjects in responds to a meal (Das and Moses, 2007). The direct effect of secreted insulin on hepatic metabolic processes is 
eliminated due to diffusion of insulin in to the peripheral circulation. This limitation of insulin is addressed by developing modified human insulins or insulin analogues which differs by one or a few amino acids from primary structure of insulin. These mimic physiologic insulin action more closely than conventional human regular insulin preparations (Rosenstock et al., 2006).

Majority of Type 2 diabetic patients require insulin therapy either conventional or insulin analogs due to destruction of $\beta$-cells in pancreas. Insulin lispro, aspart and glulusine are rapid acting insulin analogues and Insuin glargine and detemir are long acting analogues of insulin presently available in Indian market. The insulin analogs have similar potency as per dose by dose in comparison with conventional insulin, therefore, it is a common practice to use biphasic insulin twice/ thrice daily or biphasic human insulin twice a day with rapid acting human insulin before lunch (Holman et al., 2009). In various studies conducted all over the world, Insulin analogues are reported to have better efficacy and safety as compared to regular insulin therapy (Singh et al., 2009), however, substantiation of data in different geographical areas with genomic variation is yet to be established.

The aim of this study was therefore, to evaluate and compare the effectiveness and clinical safety profile of insulin analogues with regular insulin in North Indian population.

\section{MATERIAL AND METHODS}

This prospective, observational study was conducted on randomly selected diabetic patients on insulin therapy at outpatient department (OPD) of a superspeciality hospital in New Delhi, India. The aim of the study was to evaluate and compare the short term effectiveness and clinical safety profile of insulin analogues with regular insulin in North Indian population.

\section{Study sample}

The study aim, objectives, duration and procedure were explained to the prospective participants and a signed informed consent form was obtained from 94 diabetic patients on insulin therapy. Exclusion criteria for the study included if patients were mentally challenged, pregnant, below 18 years, on both insulin and oral hypoglycemic agents, refuse or unable to comply. Based on inclusion/exclusion criteria only 78 patients were enrolled in the study. There were 24 patients on biphasic insulin analogues, 33 on recombinant insulin analogues and 21 on regular insulin therapy at the commencement of the study. All the patients were observed for duration of 13 weeks.

\section{Data collection}

Data was collected from the physicians prescribing records, pathology lab reports and patient's medical profile. At the commencement of the study parameters such as base line height, weight, body mass index (BMI), blood pressure, insulin dose, number of major/minor hypoglycemic events, recent $\mathrm{HbA}_{1 \mathrm{c}}$, serum glucose: fasting and postprandial etc of the recruited patients were measured.

The efficacy of the insulin and its analogues was assessed on the basis of $\mathrm{HbA}_{1 \mathrm{c}}$, fasting and postprandial glucose values. Safety was assessed on the basis of hypoglycemic events (both minor and major) and weight changes during insulin therapy.

\section{Ethical consideration}

The study protocol was approved by institutional review board of Jamia Hamdard and by the ethical committee of Indraprastha Apollo hospital, New Delhi, India. Also all the enrolled patients were ensured confidentiality.

\section{Statistical analysis}

The statistical analyses were performed using Instat software. Student's $t$ test and Pearson Chi square tests were used to check the level of significance. Values of $\mathrm{P}<0.005$ and 0.05 were considered highly significant and significant respectively.

\section{RESULTS AND DISCUSSION}

During the 13 weeks study period, a total of 78 patients, randomized in three groups; Biphasic Analogues (BA), Insulin analogues (IA) and Regular Insulin (RI) (24, 33 and 21 patients respectively) completed the study. Duration of present study was comparatively shorter, but as per literature survey reports, efficacy and safety evaluation data exists of similar study duration (Breizel, 2004). 
Table I. Base line characteristics of participants

\begin{tabular}{lcccc}
\hline Parameters & BA & IA & RI & p- value \\
\hline OPD (numbers) & 24 & 33 & 21 & 0.223 \\
Age (years) & $50.42 \pm 1.54$ & $56.52 \pm 2.21$ & $51.71 \pm 1.95$ & \\
Sex (M/F) & $14 / 10$ & $21 / 12$ & $9 / 12$ & 0.89 \\
BMI (kg/m ${ }^{2}$ ( & $24.55 \pm 0.47$ & $26.70 \pm 0.75$ & $24.98 \pm 0.79$ & \\
Type of DM (Type 2/Type 1) & $24 / 0$ & $30 / 3$ & $21 / 0$ & $<0.001$ \\
Diabetes duration (months) & $33.25 \pm 3.31$ & $66.39 \pm 8.89$ & $63.43 \pm 11.60$ & \\
Complications (Micro/Macro) & $3 / 1$ & $9 / 6$ & $6 / 1$ & 0.96 \\
Patients classification based & & & & \\
on blood pressure & & & & \\
Optimal & 1 & 1 & 3 & \\
Normal & 14 & 11 & 11 & 0.672 \\
High Normal & 4 & 5 & 2 & \\
Hypertension & 5 & 16 & 5 & \\
Diabetic diet intake & & & & \\
$<1400$ calorie & 6 & 9 & 3 & \\
1400 to 1800 calorie & 4 & 16 & 13 & \\
$>1800$ calorie & & 8 & 5 & \\
\hline
\end{tabular}

Data on; age, Body Mass Index (BMI) and diabetes duration is expressed as Mean \pm SEM. p-value by Chi square test; $\mathrm{BA}=$ Biphasic Insulin analogue, $\mathrm{IA}=$ Insulin an alogue, RI = Regular Insulin.

The base line characteristics such as age, BMI, type of DM, diabetes duration (in months), complications (micro/macro) of the three groups are presented in table I.

Majority of the participants were male $(44 / 78)$ and were suffering from type 2 diabetes. The mean age of the patients was more than 50 years but in previous similar studies mean age was less than 50 years (Home, 2004). Male, female ratio varied between the three groups but female patients were comparatively more in RI group. Mean BMI value in BA and RI treatment groups was less than $25 \mathrm{~kg} / \mathrm{m}^{2}$, whereas in IA group the value was more than $26 \mathrm{~kg} / \mathrm{m}^{2}$.

Mean value of diabetes duration in present study was more than that of previous study (Freeman, 2010). Study participants were also classified on the basis of their blood pressure and diabetic diet intake. One third of the study population was hypertensive and approximately $80 \%$ of the diabetic patients were consuming less than 1800 calories/day as per the physician's advice and Pearson Chi square test revealed no significant difference in their dietary intake $(\mathrm{p}<0.05)$ (Table I).

Efficacy of the insulin therapy in three treatment groups was evaluated by measuring $\mathrm{HbA}_{1 \mathrm{c}}$ level, a marker for predicting the glycemic control. A significant improvement in the overall glycemic control was observed in both BA and IA groups as evidenced by decrease in $\mathrm{HbA}_{1 \mathrm{c}}$ levels from $9.94 \pm 0.40$ to $8.22 \pm 0.397 \quad(\mathrm{p}<0.005)$ and $9.94 \pm 0.53$ to $8.23 \pm 0.29 \quad(\mathrm{p}<0.005)$ respectively. Regular Insulin was not effective as analogues in terms of glycemic control that was probably due to different baseline $\mathrm{HbA}_{1 \mathrm{c}}$ levels in three treated groups. The RI treated subjects had much lower baseline $\mathrm{HbA}_{1 \mathrm{c}}$ level as compared to other two groups, thus it would be very difficult to reduce the $\mathrm{HbA}_{1 \mathrm{c}}$ levels any further. It was also observed that there was a significant percentage reduction in $\mathrm{HbA}_{1 \mathrm{c}}(17.3 \%$ and $17.2 \%$ in $\mathrm{BA}$ and IA group respectively) in analogue groups, but percentage reduction in RI group was non-significant $(2.3 \%)$ during the 13 weeks of Insulin therapy (Table II). 
Mohammad Ali Koladi

An overall statistically significant difference was requirements in the patients at the start or

Table II. Effect of insulin therapy on safety and efficacy parameters

\begin{tabular}{lccccccccc}
\hline Parameters & \multicolumn{3}{c}{ BA } & \multicolumn{3}{c}{ IA } & & \multicolumn{3}{c}{ RI } & \\
\cline { 2 - 10 } & $\begin{array}{c}\mathbf{1}^{\text {st }} \\
\text { week }\end{array}$ & $\begin{array}{l}\mathbf{1 3}^{\text {th }} \\
\text { week }\end{array}$ & $\begin{array}{c}\text { \% } \\
\text { Redu } \\
\text { ction }\end{array}$ & $\begin{array}{l}\mathbf{1}^{\text {st }} \\
\text { week }\end{array}$ & $\begin{array}{c}\mathbf{1 3}^{\text {th }} \\
\text { week }\end{array}$ & $\begin{array}{c}\text { \% } \\
\text { Redu } \\
\text { ction }\end{array}$ & $\begin{array}{c}\mathbf{1}^{\text {st }} \\
\text { week }\end{array}$ & $\begin{array}{c}\mathbf{1 3}^{\text {th }} \\
\text { week }\end{array}$ & $\begin{array}{c}\text { \% } \\
\text { Redu } \\
\text { ction }\end{array}$ \\
\hline HbA1c (\%) & 9.93 & 8.21 & 17.3 & 9.94 & 8.23 & 17.2 & 8.41 & 8.22 & 2.3 \\
Mean \pm SEM & \pm 0.40 & $\pm 0.39^{* *}$ & & \pm 0.53 & $\pm 0.29^{* *}$ & & \pm 0.28 & $\pm 0.29^{\text {ns }}$ & \\
FBS (mg/dL) & 164.00 & 165.85 & -1.1 & 194.29 & 138.14 & 28.9 & 181.95 & 195.50 & -7.4 \\
Mean \pm SEM & \pm 9.58 & $\pm 7.64^{\text {ns }}$ & & \pm 11.89 & $\pm 6.89^{* *}$ & & \pm 14.02 & $\pm 13.61^{\text {ns }}$ & \\
PPBS & 250.14 & 177.04 & 29.2 & 257.77 & 253.44 & 1.7 & 259.50 & 207.3 & 20.1 \\
(mg/dL) & \pm 13.63 & $\pm 10.39^{* *}$ & & \pm 15.43 & $\pm 14.45^{\text {ns }}$ & & \pm 22.27 & \pm 12.43 & \\
Mean \pm SEM & & & & & & & & & \\
Weight (Kgs) & 67.84 & 68.21 & -0.55 & 74.55 & 74.27 & 0.37 & 65.93 & 65.55 & 0.58 \\
Mean \pm SEM & \pm 2.15 & $\pm 2.18^{\text {ns }}$ & & \pm 2.98 & $\pm 2.82^{\text {ns }}$ & & \pm 3.13 & $\pm 2.88^{\text {ns }}$ & \\
Insulin Dose & 33.52 & 32.57 & 2.8 & 57.18 & 50.88 & 11.0 & 35.60 & 39.50 & -9.87 \\
(Units/day) & \pm 2.16 & $\pm 1.61^{\text {ns }}$ & & \pm 5.05 & $\pm 3.95^{\text {ns }}$ & & \pm 4.41 & $\pm 4.60^{\text {ns }}$ & \\
Mean \pm SEM & & & & & & & & & \\
\hline
\end{tabular}

BA = Biphasic Insulin analogue, IA = Insulin analogue, RI = Regular Insulin, SEM = Standard Error of Mean.

** Highly significant $\mathrm{P}<0.005$, * Significant $\mathrm{P}<0.05$, ns Not significant $\mathrm{P}>0.05$, Data on $13^{\text {th }}$ week compared with that on $1^{\text {st }}$ week by student' $t^{\prime}$ test.

also noted in the percentage reduction of BA versus RI and IA versus RI groups (Table III). The mean reduction from base line between BA and IA was found to be non significant.

The mean fasting blood glucose (FBS) level decreased from 194.29 to 138.15 after 13 weeks of treatment with IA. However, BA and RI failed to reduce the FBS level in the respective treatment groups. Thus it can be inferred that IA is superior to BA and RI in controlling the FBS level because of its pronounced effect on FBS percentage reduction $(28.9 \%)$. A statistically significant difference was observed in between BA vs RI and $\mathrm{BA}$ vs IA when FBS percentage reduction was compared between groups (Table III).

In case of postprandial blood sugar (PPBS), percentage reduction was more pronounced in BA group $(29.2 \%)$ closely followed by RI group (20.1\%). No significant improvement in PPBS was noted in case of insulin analogue group. (Table II and III)

There was no significant difference observed in both, weight and insulin dosage during 13 weeks of therapy. The mean initial dose requirement in analogue group was slightly higher than the RI and BA therapy groups. At the end of the study mean insulin daily dose was reduced in BA and IA groups while the opposite is observed in RI group where dose is increased to manage the hyperglycemia. Among all the groups, BA patients received the least Insulin dose (33.5232.57 units/day) and IA group was administered the highest dose (57.18-50.88 units/day). A statistically significant difference was observed when insulin dose percentage reduction was compared between groups (Table III).

None of the patients on insulin therapy reported any major hypoglycemic episode or serious adverse event. Total number of minor hypoglycemic episodes reported was 4, 7 and 11 in BA, IA and RI respectively (i.e. RI> IA $>$ BA) (Table 4). A total of $22 \mathrm{ADR}$ were reported and were classified as $22.7 \%$ highly probable, $45.45 \%$ probable, $27.30 \%$ possible and 4.45 unlikely as per Naranjo's scale (Table V). 
Table III. Comparison of percentage reduction of efficacy parameters between treated groups

\begin{tabular}{lllllll}
\hline Parameters & \multicolumn{2}{c}{$\begin{array}{c}\text { BA vs IA } \\
\text { (Percentage reduction) }\end{array}$} & \multicolumn{2}{c}{$\begin{array}{c}\text { BA vs RI } \\
\text { (Percentage reduction) }\end{array}$} & \multicolumn{2}{c}{$\begin{array}{c}\text { IA vs RI } \\
\text { (Percentage reduction) }\end{array}$} \\
\cline { 2 - 7 } & \multicolumn{2}{c}{ BA } & \multicolumn{1}{c}{ IA } & \multicolumn{2}{c}{ BA } & \multicolumn{2}{c}{ RI } & \multicolumn{2}{c}{ IA } & RI \\
\hline HbA1c (\%) & 17.36 & 17.2 & 17.36 & 2.3 & 17.2 & 2.3 \\
Mean \pm SEM & \pm 2.86 & $\pm 2.18^{\text {ns }}$ & \pm 2.86 & $\pm 1.51^{* *}$ & \pm 2.18 & $\pm 1.51^{* *}$ \\
FBS (mg/dL) & -1.1 & 28.9 & -1.1 & -7.4 & 28.9 & -7.4 \\
Mean \pm SEM & \pm 0.71 & $\pm 2.51^{* *}$ & \pm 0.71 & $\pm 2.35^{\text {ns }}$ & \pm 2.51 & $\pm 2.35^{* *}$ \\
PPBS (mg/dL) & 29.2 & 1.7 & 29.2 & 20.10 & 1.7 & 20.10 \\
Mean \pm SEM & \pm 2.00 & $\pm 0.49^{* *}$ & \pm 2.00 & $\pm 1.85^{* *}$ & \pm 0.49 & $\pm 1.85^{* *}$ \\
Weight $(\mathrm{kg})$ & -0.54 & 0.37 & -0.54 & 0.58 & 0.37 & 0.58 \\
Mean \pm SEM & \pm 0.16 & $\pm 0.24^{\mathrm{ns}}$ & \pm 0.16 & $\pm 0.41^{\mathrm{ns}}$ & \pm 0.24 & $\pm 0.41^{\mathrm{ns}}$ \\
Insulin dose & 2.8 & 11.0 & 2.8 & -9.87 & 11.0 & -9.87 \\
(Units/day) & \pm 1.19 & $\pm 1.72^{*}$ & \pm 1.19 & $\pm 1.29 *$ & \pm 1.72 & $\pm 1.29^{*}$ \\
Mean \pm SEM & & & & & & \\
\hline
\end{tabular}

$\mathrm{BA}=$ Biphasic Insulin analogue, $\mathrm{IA}=$ Insulin analogue, $\mathrm{RI}=$ Regular Insulin, $\mathrm{SEM}=$ Standard Error of Mean; ** Highly significant $\mathrm{P}<0.005$, * Significant $\mathrm{P}<0.05$, ns Not significant $\mathrm{P}>0.05$, Percentage reduction data of IA compared with BA, RI with BA, and RI with IA by student' t' test.

Table IV. Number of ADRs observed among diabetic patients

\begin{tabular}{lccc}
\hline Hypoglycemia (Number of events) & BA & IA & RI \\
\hline Major & 0 & 0 & 0 \\
Minor & 4 & 7 & 11 \\
Nocturnal & 0 & 0 & 0 \\
SAE & 0 & 0 & 0 \\
\hline
\end{tabular}

Table V Classification of 22 cases of ADRs according to Naranjo's ADR probability scale

\begin{tabular}{lcc}
\hline Assessment score & Number of ADRs & \% of ADRs \\
\hline Unlikely; $\leq 0$ & 1 & $4.45 \%$ \\
Possible; $1-4$ & 6 & $27.30 \%$ \\
Probable; 5-8 & 10 & $45.45 \%$ \\
Highly probable; $\geq 9$ & 5 & $22.72 \%$ \\
Total & 22 & 100 \\
\hline
\end{tabular}

Regular insulin has been the main stay of therapy in diabetes since the introduction but due to its relatively slow onset of action, subcutaneous injection 30 to 60 minutes before meals is required to be administered. Administration of regular insulin is not only inconvenient and unrealistic, but it poses a risk of pre meal hypoglycemia if the meal is delayed or early postprandial hyperglycemia if the injection is at meal time (Rosenstock et al., 2006). The disadvantages of the available conventional insulin preparations especially with regard to their time action profiles hamper the optimal implementation of intensive insulin therapy (Pickup and Williams, 2003). Therefore, newer insulin preparations having better efficacy, safety and versatility were developed and introduced into the therapy. 
Findings of a study conducted in 2010, that compared analogue and human insulin in controlled clinical trials and large observational studies indicate that insulin analogues provide objective benefits such as improved glycemic control, lower risk of hypoglycemia and reduced weight gain ((Freeman, 2010). These Insulin analogues may be an option for patients with problematic hypoglycemia.

In our 13 weeks of evaluation of three different types of insulin therapy, significant reduction in the $\mathrm{HbA}_{1 \mathrm{c}}$ values was obtained in $\mathrm{BA}$ and IA patients as compared to the values with RI therapy. There was no significant difference observed between BA and IA in the $\%$ reduction of $\mathrm{HbA}_{1 \mathrm{c}}$ values but IA group showed marked decrease in FBS level as compared to other two groups. However, IA could not match the BA and RI in controlling the PPBS level. The findings of our pilot study on efficacy parameters are in accordance with the earlier published reports (Breizel et al., 2004; Qayyum et al., 2008; Dills, 2001).

There were no significant clinical differences observed in safety parameters among the three groups such as body weight, insulin dose, major or nocturnal hypoglycemic episodes and serious adverse events during the study period. The numbers of minor hypoglycemic episodes reported in RI group was comparatively higher than BA and IA.

The data of this study support evidence that analogues are safer and effective choice to manage diabetes in this geographical set of population.

\section{CONCLUSION}

The results of the present study demonstrate that insulin analogues are safer and effective with regards to glycemic control and event of hypoglycemia over regular insulin. Biphasic analogues are effective in glycemic control in terms of both $\mathrm{HbA}_{1 c}$ and PPBS, where as monophasic insulin analogues are effective in glycemic control in terms of both FBS and $\mathrm{HbA}_{1 \mathrm{c}}$. These analogues are safer than regular insulin as they produced less number of minor hypoglycemic episodes.

\section{LIMITATIONS OF THIS STUDY AND RECOMMENDATION}

Considering the limitations such as short study duration and study population size, findings of the study cannot be generalized to the North Indian population. Further detailed investigation is required for the safety and effectiveness evaluation, separately in basal and meal time analogues.

\section{REFERENCES}

American Diabetes Association, 2014. Standards of medical care in diabetes2014. Diab Care 37(Suppl 1), S14-S80.

Bjork S., Kapur A., King, H., Nair J., Ramachandran A., 2003, Global policy: aspects of diabetes in India. Health Policy 66(1): 61-72.

Bretzel, R.G., Arnolds, S., Medding, J., Linn, T., 2004, A direct efficacy and safety comparison of insulin aspart, human soluble insulin and human premix insulin (70/30) in patients with type 2 diabetes. Diabetes care 27(5): 10231027.

Canadian Diabetes Association, 2003, Clinical practice guidelines for the prevention and management of diabetes in Canada. Can. J. Diabetes (Suppl 2). 27: i-S140.

Das S., Moses CR., 2007. Moses manual on diabetes mellitus. New Delhi: IJCP Group of Publications.

Dills DG., 2001, New aspects of insulin therapy in type 1 and type 2 diabetes. Current Diabetes Reports 1: 112-118.

DiPiro JT, Talbert RL, Yee GC, Matzke GR, Wells BG, Posey L. Pharmacotherapy: A pathophysiologic approach, $7^{\text {th }}$ edn. Washington: The Mc Graw-Hill Companies 2008.

Freeman JS., 2010, Are Analogue Insulins Superior to Human Insulin in Clinical Practice? Current Diabetes Reports 10: 176183.

Holman RR., Farmer AJ., Davies MJ., Levy JC., Darbyshire JL., Keenan, J.F., Paul, S.K., 2009, Three year efficacy of complex insulin regimens in type 2 diabetes. New EngJ Med 361:1736-1747. 
Home P., Bartley P., Jones DR., Broutin HH., Heeq JE., et al., 2004, Insulin detemir offers improved glycemic control compared with NPH insulin in people with type 1 diabetes: A randomized clinical trial. Diabetes Care 27 (5): 10811087.

International Diabetes Federation, 2009. Diabetes Atlas, 4th edition. India continues to be the diabetes capital of the world.

Pickup JC., Williams G., Text book of diabetes$1 \& 2$, 3rd edn. New York: Black well publishing, 2003.

Qayyum R., Bolen S., Maruthur N., Feldman, L., Wilson LM., Marinopoulos SS., 2008, Systematic Review: Comparative
Effectiveness and Safety of Premixed Insulin Analogues in Type 2 Diabetes. Ann Internal Medicine 149: 549-559.

Rosenstock J., Banarer S., Owens D., 2006, Insulin strategies in type 1 and type 2 Diabetes Mellitus. In clinical diabetes translating research in to practice (V.A. Fonseca, ed). W.B. Saunders: An imprint of elseiver. Ch.29.

Singh SR., Ahmad F., Lal A., Yu C., Bai Z., Bennet H., 2009, Efficacy and safety of insulin analogues for the management of diabetes mellitus: a meta-analysis. C.M.A.J. , 180 (4): 385-397. 